\title{
A Prospective Study to Evaluate the Predictivity of Risk Malignancy Index in Adnexal Masses
}

\author{
Narin YAR ELMASTAS ${ }^{1}$, Mehmet OBUT ${ }^{2}$, Senem YAMAN TUNC ${ }^{3}$ \\ Diyarbakir, Turkey
}

\section{ABSTRACT}

OBJECTIVE: To evaluate the efficiency of CA-125, menopausal status, ultrasound features and risk malignancy index in predicting malignancy in patients with an adnexal mass.

STUDY DESIGN: This study was designed prospectively and 212 patients who applied to our hospital and met the study criteria were included. Preoperatively RMI value was calculated for the differentiation of benign from malignant patients. The diagnosis was confirmed by histopathology. KolmogorovSmirnov, Yates correction, Pearson Chi-Square and Student's t-test were used for statistical analysis. ROC curves were drawn as diagnostic tests and the test results were presented.

RESULTS: Of 212 patients included in our study, 174 (82\%) patients' were reported as benign, 6 (3\%) borderline and $32(15 \%)$ malignant. In predicting malignancy, the malignity risk index with 200 cutoff value the sensitivity and specivity was $87 \%$ and $80 \%$ respectively. However, when the cutoff value of malignity risk index taken as 112 , the sensitivity was unchanged but the specificity increased to $90 \%$. Similarly, when CA-125's cutoff value was taken as $46 \mathrm{U} / \mathrm{mL}$, the sensitivity did not change but the specificity increased from $68 \%$ to $72 \%$.

CONCLUSION: Malignancy risk index is a method that has high sensitivity and specificity. Preoperativeop RMI calculation can provide accurate predictions for the establishment of an appropriate surgical plan for pelvic masses or referral to tertiary centers.

Keywords: Adnexal masse, Malignancy, Malignancy risk index, Ovarian cancer, Prediction

Gynecol Obstet Reprod Med 2021;27(2):169-174

\section{Introduction}

Ovarian cancer is the second most common gynecological cancer in developed countries. It is the fifth most common cancer associated with death in women and the highest mor-

\footnotetext{
${ }^{\prime}$ Health Sciences University, Diyarbakir Gazi Yasargil Training and Research Hospital, Department of Obstetrics and gynecology, Diyarbakir, Turkey

${ }^{2}$ Health Science University, Etlik Zubeyde Hanim Women Health Training and Research Hospital, Department of Obstetrics, Ankara, Turkey

3 Dicle University, Faculty of Medicine, Department of Gynecology and Obstetrics, Diyarbakir, Turkey

Address of Correspondence: Mehmet Obut

Health Science University, Etlik Zubeyde

Hanim Women Health Training and Research

Hospital, Department of Obstetrics.

06050 Ankara, Turkey.

drmehmetobut@hotmail.com
}

Submitted for Publication:13.12.2019 Revised for Publication:14.04.2020 Accepted for Publication: 02.05.2020 Online Published: 02.08.2021

ORCID IDs of the authors: NYE: 0000-0001-6400-5167

MO: 0000-0002-6925-4784 SYT: 0000-0003-2583-2770

\begin{tabular}{|c|c|}
\hline \multirow{3}{*}{ 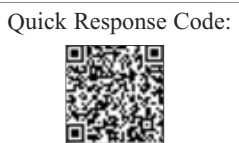 } & Access this article online \\
\hline & $\begin{array}{l}\text { Website: www.gorm.com.tr } \\
\text { e- mail: info@gorm.com.tr }\end{array}$ \\
\hline & DOI:10.21613/GORM.2020.1057 \\
\hline
\end{tabular}

How to cite this article: Yar Elmastas N. Obut M. Yaman Tunc $S$ A Prospective Study to Evaluate the Predictivity of Risk Malignancy Index in Adnexal Masses. Gynecol Obstet Reprod Med. 2021;27(2):169-174 tality among gynecological malignancies $(1,2)$. Despite the intensive studies and researches on the differentiation of benign and malignant adnexal masses preoperatively, no satisfactory standardized method has been found yet and studies are ongoing (3). If preoperatively benign and malignant masses are differentiated, the clinician can refer patients who are suspected of malignancy to the gyneco-oncologist, to allow the patient to receive appropriate treatment, and to extend the patient's life span with optimal cytoreductive treatment $(1,2)$. The final diagnosis is still possible only by histopathology. Jacobs et al. (1990) established risk of malignancy index which based on serum CA-125, menopausal status and ultrasonography (USG) findings, had higher sensitivity and specificity $(85.4 \%$ and $96.9 \%$ for $\mathrm{RMI}=200$, respectively) than any of these and stated that adnexal masses can be used to differentiate between malignant and benign and can be directed to centers necessary for more appropriate and effective surgical intervention $(4,5)$. Tingulstad et al. modified RMI 1 and developed RMI 2 (1996) and RMI 3 (1999) (6,7). Recently, Yamamoto et al. (2009) developed RMI 4 by adding tumor size to parameters (8). The major advantage of RMI is that it is uncomplicated, easy to use in practice and can be applied without costly imaging methods such as MRI or CT. RMI is probably the most widely accepted algorithm for malignant-benign differentiation of adnexal masses $(9,10)$. However, its sensitivity 
is low in nonepithelial malignant and borderline tumors (11). The best cut off value for RMI 1, RMI 2 and RMI 3 were found to be 200, and RMI 4 was found to be $450(4,6-8)$.

In this study, we aimed to evaluate the performance of RMI 3 in predicting malignant adnexal masses prospectively.

\section{Material and Method}

This is a prospective study conducted in a tertiary care hospital. The ethics committee approved the study (213/14). We obtained written informed consent from all patients before enrolment. The study was conducted in accordance with the Declaration of Helsinki. A total of 212 patients who met the study criteria were included. Preoperatively for each patient operated for adnexal mass in the Gynecology and Obstetrics Clinic of Dicle University Medical Faculty Hospital between 01.01.2012-12.31.2013 malignancy risk index was calculated. In the postoperative period, the performance of the CA-125, menopausal status, ultrasound features, and risk malignity index was evaluated by comparing it with histopathological results. Age, history, pelvic and physical examination findings and laboratory features of all patients were also recorded.

Patients who had an adnexal mass with, a history of ovarian malignancy, no tumor markers, no histopathological examination, non-gynecologic origin, and concomitant pregnancy were excluded.

The ultrasound was performed by some gynecologists before surgery and these ultrasound features were used to determine the ultrasound score. The transvaginal ultrasound was primarily performed via vaginal probe-grey scale $(6 \mathrm{MHz}$ PVT-661 VT Voluson Xario) after emptying the bladder and patients lay in the lithotomy position. Patients who could not be evaluated by vaginal ultrasonography due to the size of the mass were examined with a full bladder using a 3.6 MHz PVT375BT convex abdominal probe and grey-scale. The scoring system proposed by Tingulstad et al. (1999) for RMI 3 was used for the findings obtained in the ultrasonographic examination. According to this scoring, bilaterality, multilocularity, presence of solid component, presence of acid and metastasis were examined sonographically. The ultrasound score $(\mathrm{U})$ was calculated as 1 for $\leq 1$ criteria and 3 for $2 \geq$ criteria.

Serum CA-125 levels were measured preoperatively in all patients with an adnexal mass. The CA-125 level was determined by the electro-bone luminosity technique in RocheHitachi Modular E170 Immunological Analyzer system in serum obtained by centrifugation of venous blood sample at $4000 \mathrm{rpm}$ for 3 minutes. The serum level of CA-125 was applied directly to the calculation.

Postmenopausal status was defined as a patient who had for at least 1 year entering natural menopause or who had pre- viously undergone a hysterectomy, age 50 and over was required. For premenopausal women; $\mathrm{M}=1$, and for postmenopausal women; $\mathrm{M}=3$.

RMI was calculated as Tingulstad et al. (7) suggested $\mathrm{RMI}=(\mathrm{M}) \times(\mathrm{U}) \times(\mathrm{CA}-125)$.

We noted the intraoperative findings of each patient and sent the tissue specimen for histopathology. The final diagnosis and stage of disease were revealed from the postoperative specimen's histopathological examination. Tumors were classified according to World Health Organization (WHO) definitions and malignant tumors were graded according to the criteria of FIGO (2009) (International Federation of Gynecology and Obstetrics) (12)

\section{Statistical analysis}

The required sample size had been calculated using MEDCALC v19.2 software. Assuming an alpha of 0.05, a beta of .05 and area under roc curve $=.725$, power analysis suggested 90 participants (number of positive cases 30, and the number of negative cases 60 participants) are required. Statistical analysis was performed using SPSS 15.0 for Windows (SPSS Inc., Chicago, IL, the USA). Descriptive statistics of continuous variables were shown with mean and standard deviation (SD) values. Yates correction and Pearson chi-square tests were used for the analysis of the cross tables. The assumption of the normal distribution of data was tested by the KolmogorovSmirnov test. Student's t-test was used to compare the mean values of the two groups. ROC curves were drawn as diagnostic tests and the test results were presented. Hypotheses were bi-directional and $p \leq 0.05$ was considered statistically significant.

\section{Results}

During the study period, 212 patients were found to meet the study criteria. Postoperative histopathological results were reported to be benign in 174 patients $(82 \%)$, borderline in 6 patients $(3 \%)$, and malignant in 32 patients $(15 \%)$. Borderline tumors differ histologically from benign tumors because they contain abnormal epithelium and have low malignant potential (13). In addition surgical approach of borderline tumors is similar to malignant tumors, therefore these cases included in the malignant tumors group. The rate of early-stage cases (stage 1-2 ovarian tumors) in the malignant masses was 39\% and rate of advanced-stage cases (stage III, IV and metastatic ovarian tumors) was $61 \%$.

There was a significant difference between the mean age of the malignant and benign group and was $72 \pm 14.6$ and $42 \pm 15.8$ respectively $(p<0.05)$.

Serous cystadenoma (18.8\%) and dermoid cysts (18.8\%) were the most common benign masses, followed by serous cystadenocarcinoma $(9.4 \%)$. Borderline tumors accounted for 
$2.8 \%$ of malignant ovarian tumors. Of these $2.3 \%$ were serous type and $0.4 \%$ were mucinous. Epithelial ovarian tumors were the most common ovarian malignant and in this group the most common type was serous adenocarcinoma was (62.5\%), followed by mucinous cystadenocarcinoma (15.6\%) (Table I).

Table II shows the distribution of malignant tumors stage. Stage 4 was the most common stage for surgical staging of malignant adnexal masses, followed by stage 1 cases with borderline tumors.

The receiver operating characteristic analysis of the ultrasound features that solid component, bilaterality, multilocularity, presence of ascites and metastasis showed the values of area under the curve $0.750,0.656,0.550,0,739$, and 0.591 respectively (Figure 1).

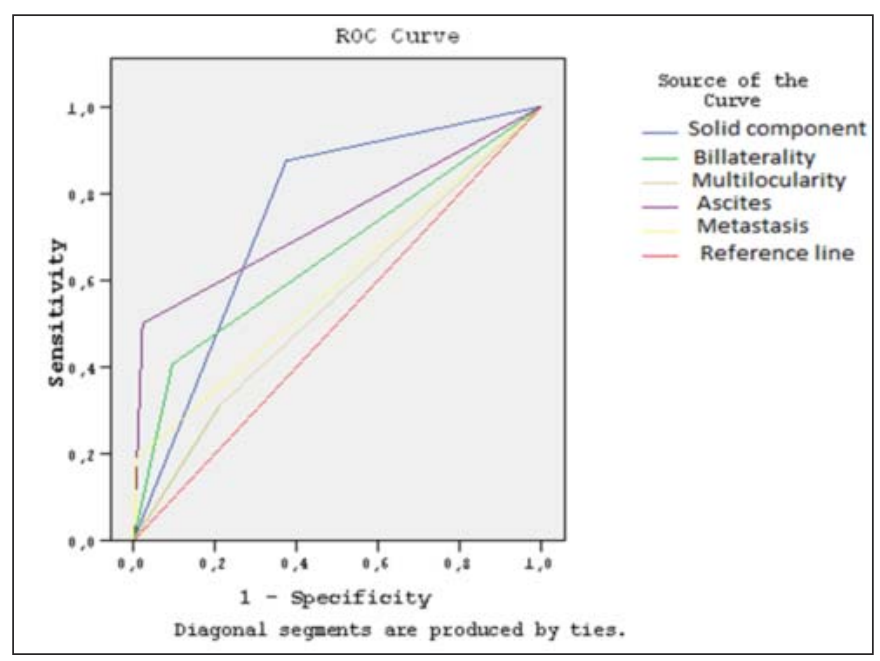

Figure 1: Receiver operator curve showing the performance of ultrasound features for the predicting malignancy

Table I: Distribution of benign, borderline, and malignant adnexal masses

\begin{tabular}{|c|c|c|c|c|c|}
\hline \multicolumn{3}{|l|}{ Benign tumors } & \multicolumn{3}{|l|}{ Malignant-borderline tumors } \\
\hline Histological type & $\mathrm{n}$ & $\%$ & Histological type & $\mathrm{n}$ & $\%$ \\
\hline Nonneoplastic & 45 & 25.8 & Borderline & 6 & 100 \\
\hline - hemorrhagic cyst & 17 & 9,8 & - Serous borderline & 5 & 83.3 \\
\hline - endometrioma & 16 & 9.2 & - Mucinous borderline & 1 & 17.7 \\
\hline - tuba ovarian abscess/hydrosalpinx & 5 & 2.9 & Total & 6 & 100 \\
\hline -Ovarian torsion & 5 & 2.9 & Malignant & 32 & 100 \\
\hline -Ectopic pregnancy & 2 & 1.1 & Epithelial tumor & & \\
\hline Neoplastic & 129 & 74.2 & - Epithelial adenocarcinoma & 27 & 84.4 \\
\hline & & & - Serous cystadenocarcinoma & 2 & 6.3 \\
\hline - Germ cell tumors & 44 & 25.3 & - Mucinous & 20 & 62.5 \\
\hline - mature cystic teratoma & 40 & 23 & cystadenocarcinoma & 5 & 15.6 \\
\hline -Struma ovarii & 4 & 2.3 & Sex-cord stromal tumor & 2 & 6.3 \\
\hline Epithelial tumors & 81 & 46.5 & - Granulosa cell tumor & 2 & 6.3 \\
\hline - serous cyst & 22 & 12.6 & Metastatic ovarian tumors & 2 & 6.2 \\
\hline - serous cystadenoma/adenofibroma & 40 & 23 & (colon, gastric, cervix) & & \\
\hline - mucinous cystadenoma & 18 & 10.3 & - Epidermoid carcinoma & 1 & 3.1 \\
\hline - Brenner's tumor & 1 & 0.6 & -Signet ring cell & 1 & 3.1 \\
\hline Sex-cord stromal tumor & 4 & 2.9 & Another & 1 & 3.1 \\
\hline -fibroma & 4 & 2.9 & - carcinosarcoma & 1 & 3.1 \\
\hline Total & 174 & 100 & Total & 38 & 100 \\
\hline
\end{tabular}

Table II: Distribution of malignant adnexal masses according to the surgical stage

\begin{tabular}{|c|c|c|c|c|c|c|}
\hline \multirow[b]{2}{*}{ Type } & \multicolumn{6}{|c|}{ Surgical stage } \\
\hline & & Stage 1 & Stage 2 & Stage 3 & Stage 4 & Total \\
\hline \multirow[t]{2}{*}{ malignant } & $\mathrm{n}:$ & 6 & 3 & 5 & 18 & 32 \\
\hline & $\%$ : & $18.8 \%$ & $9.4 \%$ & $15.6 \%$ & $56.3 \%$ & $100.0 \%$ \\
\hline \multirow[t]{2}{*}{ borderline } & $\mathrm{n}:$ & 5 & 1 & 0 & 0 & 6 \\
\hline & $\%:$ & $83.3 \%$ & $16.7 \%$ & $0.0 \%$ & $0.0 \%$ & $100.0 \%$ \\
\hline \multirow[t]{2}{*}{ Total } & $\mathrm{n}:$ & 11 & 4 & 5 & 18 & 38 \\
\hline & $\%$ : & $28.9 \%$ & $10.5 \%$ & $13.2 \%$ & $47.4 \%$ & $100.0 \%$ \\
\hline
\end{tabular}


Table III shows the ultrasonographic morphological findings in benign and malignant tumors and showed a statistically significant difference between benign and malignant masses in all parameters except multilocularity. Menopausal status, CA-125 levels, and RMI were significantly different between malign and benign groups $(p<0.001)$.

The RMI showed higher sensitivity and specificity than any its components separately. The optimal threshold value calculated according to the ROC curve of RMI was 112 and at this point the sensitivity and specificity was $90 \%$ and $80 \%$ respectively in predicting malignancy (Table IV), (Figure 2).

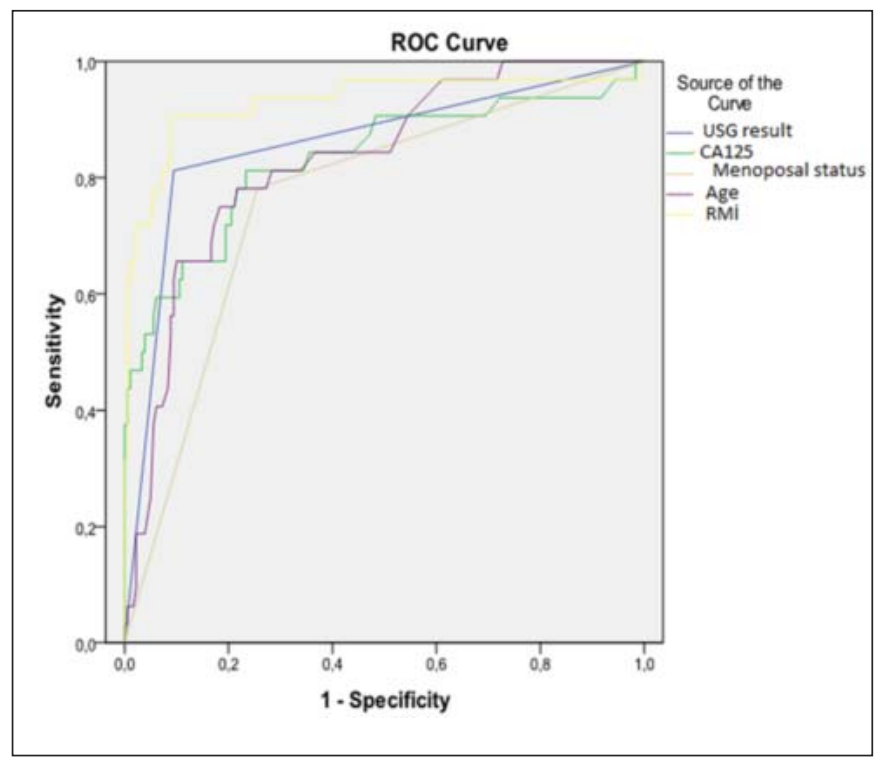

Figure 2: Receiver operator curve showing the performance of the risk of malignancy index, CA-125, ultrasound score, age, and menopausal status.
Table IV: The cut-off point, sensitivity, specificity, and area under the curve of studied parameters

\begin{tabular}{lccccc}
\hline Parameters & $\begin{array}{c}\text { Cut-off } \\
\text { point }\end{array}$ & $\begin{array}{c}\text { Sensitivity } \\
\%\end{array}$ & $\begin{array}{c}\text { Specificity } \\
\%\end{array}$ & AUC & p \\
\hline RMI & 112 & 90 & 80 & .931 & $<0.001$ \\
USG features & $2-5$ & 80 & 82 & .859 & $<0.001$ \\
CA-125 & 46 & 81 & 77 & .832 & $<0.001$ \\
Age & 54 & 75 & 79 & .830 & $<0.001$ \\
Menopause & 3 & 78 & 75 & .763 & $<0.001$
\end{tabular}

AUC: Area under the curve, RMI: Risk of malignancy index

\section{Discussion}

The main clinical dilemma is the efforts to detect ovarian cancer in the early period and the increase in morbidity and mortality of the number of unwanted surgical interventions. There has been an increasing consensus on the development of new diagnostic methods for a better selection of these patients. Malignant epithelial ovarian tumors peak between 60-70 years of age. They are rarely seen under the age of 40 (14). In our study, the mean age was $42 \pm 15$ for benign and was $71 \pm 14$ years for malignant cases. The mean age of the patients with malignant masses was found to be more advanced and consistent with the literature.

Ovarian malignancy rate increases significantly in postmenopausal women and over 50 years of age (15). In the literature, a significant relationship was found between menopausal status and malignancy. In the studies conducted, the predictivity of menopausal status for malignancy, the sensitivity ranged from $48.6 \%$ to $80.6 \%$, and the specificity

Table III: Comparison of USG, menopause, CA-125, and RMI in patients with benign and malignant masses

Variable

Benign

$\mathrm{n}(\%)$

Multilocularity

Bilaterality

Solid areas

Ascites

Metastases

0 or 1 USG findings

USG findings $\geq 2$

CA $125<35$

CA $125>35$

premenopausal

postmenopausal

$\mathrm{RMI}<200$

$\mathrm{RMI} \geq 200$
$132(62.2 \%)$

$42(19.8 \%)$

$161(76.0 \%)$

$$
\begin{gathered}
35(16.5 \%) \\
16(7.5 \%) \\
64(30 \%) \\
2(1 \%) \\
0(0 \%) \\
160(75.4 \%) \\
14(6.6 \%)
\end{gathered}
$$

$116(54.7 \%)$

$58(27.3 \%)$

$13(6.1 \%)$
Malign

n (\%)

Ultrasonographic Morphology

$13(6.1 \%)$

$14(6.6 \%)$

$31(14.6 \%)$

$18(8.4 \%)$

$7(3.3 \%)$

$9(4.3 \%)$

$29(13.7 \%)$

CA 125

$9(4.3 \%)$

$29(13.7 \%)$

Menopausal status

$9(4.3 \%)$

$29(13.7 \%)$

RMI

$6(2.8 \%)$

$32(15.1 \%)$

Total

n (\%)

$p$

$48(22.6 \%)$

$30(14 \%)$

$95(44.8 \%)$

$20(9.4 \%)$

$7(3.3 \%)$

$169(79.7 \%)$

$43(20.3 \%)$

$125(59.0 \%)$

$87(41.0 \%)$

$141(66.5 \%)$

$71(33.5 \%)$

$167(78.8 \%)$

$45(21.2 \%)$
0.085

$<0.001$

$<0.001$

$<0.001$

$<0.001$

$<0.001$

$<0.001$

$<0.001$

$<0.001$

$<0.001$

$<0.001$

$<0.001$

$<0.001$ 
ranged from $52.5 \%$ to $78.9 \%(4-7,16-19)$. In our study, consistent with the literature, the sensitivity and specifity was $78 \%$ and $75 \%$ respectively for menopausel status in predicting malignancy $(p<0.001)$. We, therefore, recommend a careful gynecological examination of pelvic masses in postmenopausal group.

Ultrasonography is the most widely accepted and commonly used imaging modality in the differential diagnosis of adnexal masses. However, the quality of the ultrasound device and the experience of the ultrasonographer are important. Besides, the morphological images observed on ultrasonography show close similarity with the gross mass, they do not always coincide with the histological diagnosis. Therefore, it is the most subjective and person dependent parameter among the parameters in RMI.

In our study, bilaterality, solid area, ascites, metastasis, and multilocularity features of adnexal masses were evaluated ultrasonugraphically. Multilocularity was not statistically significant in predicting malignancy $(p=0.367)$. The most powerful parameter of ultrasound finding was the presence of a solid component $(p<0.001)$ ( $\mathrm{AUC}=0.750)$, although other parameters were also significant in predicting malignancy. Accordingly, we think that the sensitivity and specificity of RMI can be increased by a different weighting of ultrasonographic findings.

In our study, the sensitivity and specificity of the USG score for predicting malignancy were $80 \%$ and $82 \%$, respectively. The sensitivity for the USG score in the literature ranges between $43 \%$ and $93.7 \%$ and the specificity ranges from $82 \%$ to $89 \%(4-7,16-19)$.

CA-125 is a high molecular weight glycoprotein and has been used for many years in the follow-up and recurrence of ovarian cancer. The sensitivity and specificity of CA-125 are increased in advanced-stage ovarian cancer (stage 3-4). The specificity is lower in premenopausal patients and younger patients. In the literature, the sensitivity varies between 51\% and $100 \%$ and the specificity varies between $53.5 \%$ and $94 \%$ $(4,6,7,16-21)$. In our study, sensitivity and specificity were found $81 \%$ and specificity $68 \%$ with $35 \mathrm{U} / \mathrm{mL}$ cutoff value of CA125. However, in our study, with $46 \mathrm{U} / \mathrm{mL}$ cutoff value, the sensitivity and specificity was found $81 \%$ and $77 \%$ respectively, and the area under the curve was 0.832 in ROC analysis. We think that this result is due to the relatively younger age of our patients.

Many studies suggest a cuttoff value of 200 of the optimal efficacy threshold for RMI. In the studies RMI evaluated found that; Jacobs et al. (1990) ( $\mathrm{n}=143)$, sensitivity $85.5 \%$ and specificity 96.9\%, Davies et al. (1993) ( $\mathrm{n}=124)$ sensitivity $87 \%$ and specificity 89\%, Tingulstad et al. (1996) $(\mathrm{n}=173)$ sensitivity $71 \%$ and specificity $96 \%$, Tingulstad et al. (1999) $(n=365)$ sensitivity $71 \%$ and specificity $92 \%$, Morgante et al.
(1999) $(\mathrm{n}=124)$ sensitivity $58 \%$ and specificity $95 \%$, Manjunath et al (2000) $(\mathrm{n}=152)$ sensitivity $73 \%$ and specificity $91 \%$, Ma et al. (2003) $(\mathrm{n}=140)$ sensitivity $87.3 \%$ and specificity $84.4 \%$, Torres et al. (2003) $(n=158)$ sensitivity $73 \%$ and specificity $86 \%$, Andersen et al. (2003) $(\mathrm{n}=180)$ sensitivity $70.6 \%$ and specificity $87.7 \%$, Obeidat et al. (2004) $(n=100)$ sensitivity $90 \%$ and specificity $89 \%$, Semavi et al. (2005) $(\mathrm{n}=286)$ sensitivity 71.7 and specificity $80.5 \%$, Hakansson et al. (2012) ( $n=1103)$ sensitivity $92 \%$ and specificity $82 \%(20)$. Guraslan et al. (2017) found that when the cut-off value of RMI was taken as 200 the sensitivity and specificity was $60 \%$ and $90 \%$ respectively, but when the cut-off value of RMI was taken as 100, at this point in ROC analysis the area under the curve was maximum, the sensitivity increased to $80 \%$ and specificity $81.4 \%$ (22). Similarly, in our study when the cutoff value of the RMI was taken as 200 , the sensitivity and specificity were found to be $87 \%$ and $80 \%$, respectively but when the cutoff value of the RMI was taken as 112 , the sensitivity increased to $90 \%$ and the specificity to $80 \%$. Accordingly, with 112 cutoff value of RMI two abscess, two mature cystic teratomas, two endometriomas and one serous cystadenoma would be misdiagnosed as malignant masses but two serous cystadenocarcinomas and one epithelial adenocarcinoma would be diagosed correctly. In this study, it was found that RMI 112 should be selected as a threshold value, but further studies are needed for this idea.

The limitations of the study were its hospital-based nature which predisposes to referral bias and increased prevalence of malignancies compared to the general population, and the operations were not performed by some surgeon

The strengths of this study were that the study was prospective, single-centered, and all ultrasonographers were performed by a single specialist.

\section{Conclusion}

In our study, when the cutoff value of CA-125 was taken as $46 \mathrm{U} / \mathrm{mL}$, the sensitivity did not change but the specificity increased from $68 \%$ to $72 \%$. The RMI had high sensitivity and specifity with 200 cutoff value but; when the cutoff value was taken as 112 the specificity did not change but the sensitivity icreased from $87 \%$ to $90 \%$.

\section{Acknowledgments: None}

Funding: We did not receive funding from any institution. Author contribution: NYE: Study conception and design, acquisition of data, analysis and interpretation of data, MO: Study concept and design, drafting of the manuscript, critical revision, acquisition of data, analysis, and interpretation of data, SYT: Analysis and interpretation of data, study concept and design, critical revision.

Conflict of Interest: The authors declare that there is no conflict of interest. 


\section{References}

1. American College of Obstetricians and Gynecologists' Committee on Practice Bulletins-Gynecology. Practice Bulletin No. 174: Evaluation and Management of Adnexal Masses. Obstet Gynecol. 2016;128(5):e210-e226. doi: 10. 1097/AOG.0000000000001768.

2. Rossing MA, Wicklund KG, Cushing-Haugen KL, Weiss NS. Predictive value of symptoms for early detection of ovarian cancer. J Natl Cancer Inst. 2010;102(4):222-9. doi: 10.1093/jnci/djp500.

3. Aktürk E, Karaca RE, Alanbay I, Dede M, Karaşahin E, Yenen MC, et al. Comparison of four malignancy risk indices in the detection of malignant ovarian masses. J Gynecol Oncol. 2011;22(3):177-82. doi: 10.3802/jgo. 2011.22.3.177.

4. Jacobs I, Oram D, Fairbanks J, Turner J, Frost C, Grudzinskas JG. A risk of malignancy index incorporating CA 125, ultrasound and menopausal status for the accurate preoperative diagnosis of ovarian cancer. Br J Obstet Gynaecol. 1990;97(10):922-9. doi: 10.1111/j.1471-0528. 1990.tb02448.x.

5. Davies AP, Jacobs I, Woolas R, Fish A, Oram D. The adnexal mass: benign or malignant? Evaluation of a risk of malignancy index. Br J Obstet Gynaecol. 1993;100 (10):927-31. doi: 10.1111/j.1471-0528.1993.tb15109.x.

6. Tingulstad S, Hagen B, Skjeldestad FE, Onsrud M, Kiserud T, Halvorsen T, et al. Evaluation of a risk of malignancy index based on serum CA125, ultrasound findings and menopausal status in the pre-operative diagnosis of pelvic masses. Br J Obstet Gynaecol. 1996;103(8):82631. doi: 10.1111/j.1471-0528.1996.tb09882.x.

7. Tingulstad S, Hagen B, Skjeldestad FE, Halvorsen T, Nustad K, Onsrud M. The risk-of-malignancy index to evaluate potential ovarian cancers in local hospitals. Obstet Gynecol. 1999;93(3):448-52. PMID: 10074998.

8. Yamamoto Y, Yamada R, Oguri H, Maeda N, Fukaya T. Comparison of four malignancy risk indices in the preoperative evaluation of patients with pelvic masses. Eur J Obstet Gynecol Reprod Biol. 2009;144(2):163-7. doi: 10. 1016/j.ejogrb.2009.02.048.

9. Geomini P, Kruitwagen R, Bremer GL, Cnossen J, Mol $\mathrm{BW}$. The accuracy of risk scores in predicting ovarian malignancy: a systematic review. Obstet Gynecol. 2009;113 (2 Pt 1):384-94. doi: 10.1097/AOG.0b013e318195ad17.

10. Al-Asadi JN, Al-Maliki SK, Al-Dahhhan F, Al-Naama L, Suood F. The accuracy of risk malignancy index in prediction of malignancy in women with adnexal mass in Basrah, Iraq. Niger J Clin Pract. 2018;21(10):1254-9. doi: 10.4103/njcp.njcp_424_16.

11. Meray O, Türkçüoğlu I, Meydanlı MM, Kafkaslı A. Risk of malignancy index is not sensitive in detecting non-ep- ithelial ovarian cancer and borderline ovarian tumor. J Turk Ger Gynecol Assoc. 2010;11(1):22-6.

12. FIGO Committee on Gynecologic Oncology. Current FIGO staging for cancer of the vagina, fallopian tube, ovary, and gestational trophoblastic neoplasia. Int $\mathrm{J}$ Gynaecol Obstet. 2009;105(1):3-4. doi: 10.1016/j.ijgo. 2008.12.015.

13. Harris R, Whittemore AS, Itnyre J. Characteristics relating to ovarian cancer risk: collaborative analysis of 12 US case-control studies. III. Epithelial tumors of low malignant potential in white women. Collaborative Ovarian Cancer Group. Am J Epidemiol. 1992;136(10):1204-11. doi: 10.1093/oxfordjournals.aje.a116428.

14. Kurjak A, Kupesic S, Sparac V, Bekavac I. Preoperative evaluation of pelvic tumors by Doppler and three-dimensional sonography. J Ultrasound Med. 2001;20(8):829-40. doi: 10.7863/jum.2001.20.8.829.

15. Siegel RL, Miller KD, Jemal A. Cancer statistics, 2018. CA Cancer J Clin. 2018;68(1):7-30. doi: 10.3322/caac. 21442.

16. Morgante G, la Marca A, Ditto A, De Leo V. Comparison of two malignancy risk indices based on serum CA125, ultrasound score and menopausal status in the diagnosis of ovarian masses. Br J Obstet Gynaecol. 1999;106(6):5247. doi: 10.1111/j.1471-0528.1999.tb08318.x.

17. Manjunath AP, Pratapkumar, Sujatha K, Vani R. Comparison of three risk of malignancy indices in evaluation of pelvic masses. Gynecol Oncol. 2001;81(2):225-9. doi: 10.1006/gyno.2001.6122.

18. Ma S, Shen K, Lang J. A risk of malignancy index in preoperative diagnosis of ovarian cancer. Chin Med J (Engl). 2003;116(3):396-9. PMID: 12781045.

19. Torres JC, Derchain SF, Faundes A, Gontijo RC, Martinez EZ, Andrade LA. Risk-of-malignancy index in preoperative evaluation of clinically restricted ovarian cancer. Sao Paulo Med J. 2002;120(3):72-6. doi: 10.1590/s151631802002000300003.

20. Håkansson F, Høgdall EV, Nedergaard L, Lundvall L, Engelholm SA, Pedersen AT, et al. Risk of malignancy index used as a diagnostic tool in a tertiary centre for patients with a pelvic mass. Acta Obstet Gynecol Scand. 2012;91(4):496-502. doi: 10.1111/j.1600-0412.2012. 01359.x.

21. Karakaya BK, Ozgu E, Kansu HC, Evliyaoglu O, Sarikaya E, Coskun B, et al. Evaluation of Probably Benign Adnexal Masses in Postmenopausal Women. Avaliação de massas anexiais benignas em mulheres pós-menopáusicas. Rev Bras Ginecol Obstet. 2017;39(5):229-34. doi: 10.1055/s-0037-1601454.

22. Guraslan H, Şentürk M.B, Yaşar L. Calculation of risk of malignancy index in our clinic. Dicle Medical Journal. 2017;44(2)151-8. doi: 10.5798/dicletip.319736. 